\title{
Numerical Study on Wind-Induced Noise of High-Rise Building Curtain Wall with Outside Shading Devices
}

\author{
Wei $X u^{1,2}$ and Feng $X u \mathbb{D}^{3}$ \\ ${ }^{1}$ School of Civil Engineering and Transportation, South China University of Technology, Guangzhou 510006, China \\ ${ }^{2}$ Guangdong Provincial Academy of Building Research Group Co., Ltd., Guangzhou 510500, China \\ ${ }^{3}$ School of Civil and Environmental Engineering, Harbin Institute of Technology Shenzhen, Shenzhen 518055, China \\ Correspondence should be addressed to Feng Xu; xufeng_hit@163.com
}

Received 7 March 2018; Revised 21 May 2018; Accepted 31 May 2018; Published 8 July 2018

Academic Editor: Sergio De Rosa

Copyright (C) 2018 Wei Xu and Feng Xu. This is an open access article distributed under the Creative Commons Attribution License, which permits unrestricted use, distribution, and reproduction in any medium, provided the original work is properly cited.

\begin{abstract}
Perforation metal plates with dense holes are often used as external curtain walls of high-rise buildings. When air flow passes through these holes at a high speed, complex vortex is generated and causes a significant issue of wind-induced noise. In this study, both Reynolds-averaged Navier-Stokes (RANS) simulations and large-eddy simulations (LES) were conducted to study flow around high-rise buildings with an external sunshade curtain wall. First, wind speed distributions at the height of a typical level under 16 wind directions were acquired. Then, the maximum wind speed ratio and its corresponding azimuth were identified. Second, the sound pressure levels in the vicinity of the shading devices with two types of perforation plate schemes were calculated to evaluate the acoustic characteristics by using the FW-H equation to simulate sound generation and propagation. The results indicate that the maximum wind speed around the buildings exists at the building corners, and the maximum wind speed ratio is 2.8 observed at 0 -degree wind direction. Under two different wind conditions, the aeroacoustic performance of perforation plate is enhanced with reducing end plate size and increasing aperture size. The overall sound pressure level (OSPL) and A-weighted sound pressure level (ASPL) around the shading devices are $80 \mathrm{~dB}$ and $68 \mathrm{~dB}(\mathrm{~A})$, respectively, for the improved perforation plate scheme under the 1-year return period maximum speed, which are changed to $58 \mathrm{~dB}$ and $45 \mathrm{~dB}(\mathrm{~A})$ under the annual average speed. Therefore, it is believed that perforation plates with small end plate size and large aperture size are desirable for the noise prevention design of shading devices.
\end{abstract}

\section{Introduction}

Efficient use of energy during the entire life cycle of buildings is imperative due to increasing energy demands in the construction industry [1]. The main factors for designing energy-efficient buildings are walls, roof, orientation, size of openings, ratio of window/wall area, and shading devices [2, 3]. Shading devices should be designed to maximize shading and hence minimize heat gain in summer, while maximizing indoor sunshine in order to maximize heat gain in winter [4]. To enhance the performance of shading devices, perforation metal plates with dense holes are often used as the curtain walls of high-rise buildings, as shown in Figure 1. At the upper levels of high-rise buildings, wind exhibits strong fluctuations due to high wind speeds $[5,6]$. When wind passes through the holes, violent irregular vortex shedding occurs and the wind fluctuation itself can generate a large aeroacoustic [7], which is one type of wind-induced noises.

As reported in a number of recent studies, noise pollution continues to be a major health issue in urban area, especially areas close to road traffic $[8,9]$, railway traffic $[10,11]$, and airport $[12,13]$. The detrimental effects produced by noise to health are well-known, such as annoyance [14], sleep disorders with awakenings, learning impairment [15], and hypertension ischemic heart disease [16]. Furthermore, wind-induce noise is comparable to wind turbine noise and is recognized as a very highly annoying noise source [17]. Apparently, wind-induced noise beyond a certain threshold significantly affects human living inside buildings. Therefore, in the design phase, it is crucial to carefully select the type of shading devices for buildings in order to control windinduced noise under an acceptable level. 


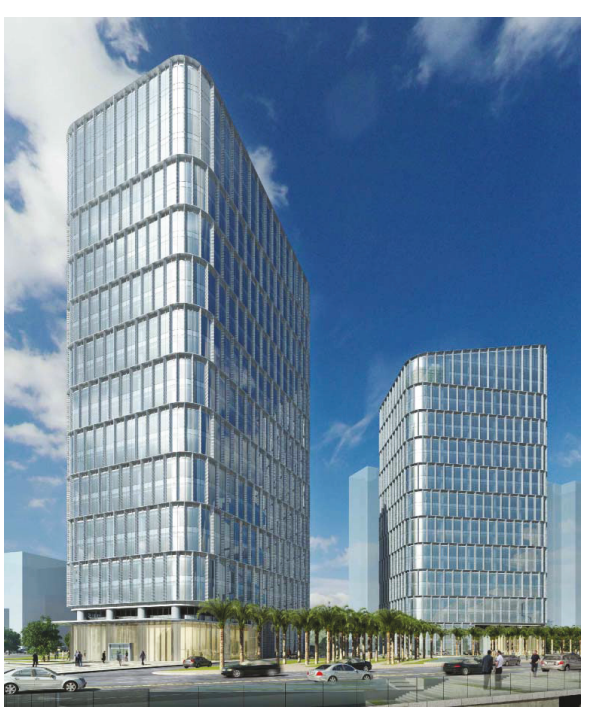

(a) Shading devices outside the curtain wall of buildings

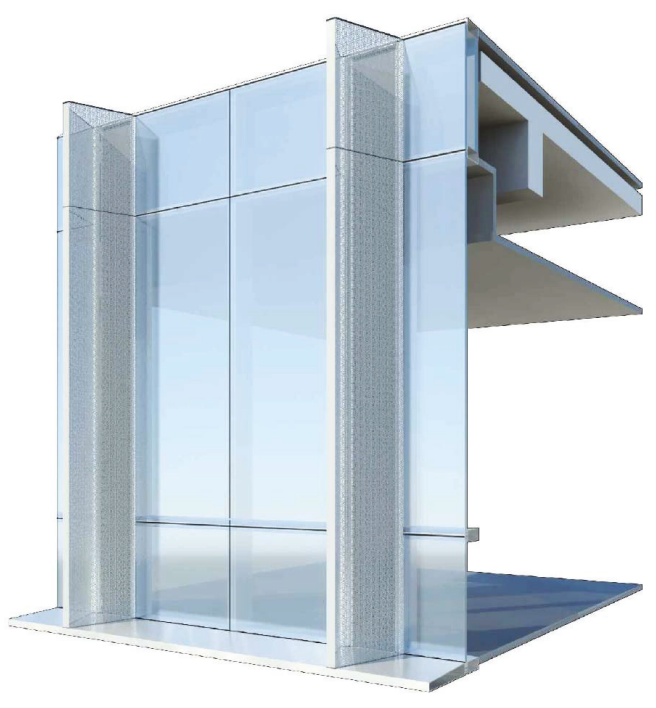

(b) Perforated plates and curtain walls

Figure 1: Curtain wall system with shading devices for energy conservation in high-rise buildings.

The research methods for wind-induced noise are similar to other studies in the field of wind engineering, and they are classified into three approaches: field measurement, wind tunnel test, and numerical simulation. Usually, winddriven ambient noise in the natural environment is generally obtained by the method of field measurement [18-21]. Because the noise of a microphone affects the accuracy of the noise measurements in an outdoor environment [22, 23], Alamshah et al. [24] invented a new approach to distinguish the contribution of the wind-induced noise from an acoustic signal by the incoherent output power analysis of two microphone signals. An arrangement of minimizing the windinduced noise was obtained by a series of indoor experiments in a small anechoic wind tunnel. Chen et al. [25] made an acoustic imaging which was performed in a classical closedsection wind tunnel that had been extensively modified using specifically designed liners on the walls of the test section. Liu et al. [26] designed a small-scale aeroacoustic wind tunnel to study both aerodynamic and aeroacoustic performance of aircraft components or scaled models. CansevKüçükosman et al. [27] developed a remote microphone technique for aeroacoustic measurements in large aerodynamic wind tunnels. In the technique, the microphone and its connecting line to the sensing port were fitted within an aerodynamically streamlined fairing. However, due to the complexity of the air flow around buildings and limitation of space size of the wind tunnel, the acoustic wind tunnel is rarely used to study the wind-induced noise of buildings with shading devices.

Under this background, numerical simulation has become an important approach to study wind-induced noise. With the rapid development of computational fluid dynamics, significant progress has been made in the numerical simulation of wind-induced noise, and its application in the field of engineering is becoming increasingly extensive, such as in the study on aerocrafts [28], vehicles [29], and wind turbines [30]. Zhang et al. [31] used a broadband noise source model based on Lighthill's acoustic theory to perform numerical simulations of the aerodynamic noise sources for a high-speed train. In this method, the near-field unsteady flow around a high-speed train was analyzed based on a delayed detached-eddy simulation (DDES) using the finite volume method with high-order difference schemes, while the far-field aerodynamic noise from a high-speed train was predicted using a computational fluid dynamics (CFD)/Ffowcs Williams-Hawkings (FW-H) acoustic analogy. Mohamed [32] introduced an innovative design of the lift VAWTs (vertical axis wind turbines) to reduce the noise emissions. The aerodynamics field of the new design had been investigated numerically to obtain the generated noise from new blades. Hashem et al. [33] introduced an aeroacoustic computational study that investigates the noise caused by one of the most promising wind energy conversion concepts, namely, the "WindLens" technology. Comparison of the noise emitted from the bare wind turbine and different types of Wind-Lens turbine revealed that the Wind-Lens generated higher noise intensity. These above work has made a good application to simulate the wind-induced noise and solved a series of problems in engineering, but there is not much research on the wind-induced noise of building enclosure. Only a few relatively simple attempts have been found in the public literature. Li et al. [34] performed a numerical simulation of a rectifying device with a perforation plate. The application range on the downstream side of the perforation plate was studied based on a numerical simulation of the resistance characteristics of perforation plates. Qu [35] researched the effects of built environment morphology on wind turbine noise exposure at building facades. Wang et al. [36] revealed the mechanism of the flow-induced sunroof buffeting noise of a simplified cavity model through computational and 
experimental studies. In comparison, less attention had been paid to wind-induced noise in buildings. Kim et al. [37] performed a large-eddy simulation to obtain the wind field and then predicted the wind-induced noise around a building by solving the SYSNOISE Rev5.6Beta program. The comparison between the experimental and numerical simulation results showed that the peak sound pressure level (SPL) exhibited very similar trends. Martello et al. [38] analyzed the direct and flanking sound transmission between rooms with curtain wall facades.

In this paper, three buildings with a height of about $100 \mathrm{~m}$ in Guangzhou of China are selected as research objects, shown in Figure 1. The aeroacoustic performance of the triangular hollow cavity enclosed by perforation aluminum plates on the facade of the curtain wall is studied in detail. The relevant evaluation indexes of wind-induced noise are obtained and compared by simulating the different perforation plate schemes, which provides a useful reference for the optimization of curtain wall system with external sunshade and plays a good guiding role for the actual engineering design.

\section{Numerical Simulation Method}

2.1. Governing Equations of Fluid. In the field of simulation of the flow around buildings, a Newton fluid with a shear stress is considered as an incompressible fluid. The basic governing equation is the Navier-Stokes equation, including the continuity and momentum equations. The commonly used methods for turbulence simulation include the Reynoldsaveraged Navier-Stokes method (RANS) and large-eddy simulation (LES). In view of the two scales of flow phenomena and efficiency of computation, the RANS method is used to calculate the flow field around the buildings. The LES method is used to calculate the flow field around the perforation plates. Among these, formula (1) is the continuity equation of an incompressible fluid, and formula (2) is the momentum equation with time average considered in RANS. Formula (3) is the momentum equation in LES.

$$
\begin{gathered}
\frac{\partial\left(\rho u_{i}\right)}{\partial x_{i}}=0 \\
\frac{\partial}{\partial x_{j}}\left(\rho u_{i} u_{j}\right)=-\frac{\partial p}{\partial x_{i}}+\frac{\partial}{\partial x_{j}}\left(\mu \frac{\partial u_{i}}{\partial x_{j}}-\rho \overline{u_{i}^{\prime} u_{j}^{\prime}}\right) \\
\frac{\partial \rho u_{i}}{\partial t}+\frac{\partial}{\partial x_{j}}\left(\rho u_{i} u_{j}\right)=-\frac{\partial p}{\partial x_{i}}+\frac{\partial}{\partial x_{j}}\left(\mu \frac{\partial u_{i}}{\partial x_{j}}\right)-\frac{\partial \tau_{i j}}{\partial x_{j}}
\end{gathered}
$$

where $\rho$ is the air density, $u_{i}$ is the mean velocity, $u_{i}^{\prime}$ is the fluctuating velocity, $p$ is the mean pressure, and $\mu$ is the kinematic viscosity coefficient. The group of equations is not closed in formula (2) owing to the introduction of the Reynolds stress term considering the effect of the fluctuating variables. Therefore, only when the turbulence model is introduced, the equation can be calculated and solved after the equations have been closed. In this study, the renormalization group ( $\mathrm{RNG}) k-\varepsilon$ two-equation model is used. In formula (3), $\tau_{i j}$ is the subgrid Reynolds stress. In this study, the Smagorinsky-Lilly subgrid model is used to represent the subgrid Reynolds stress.
2.2. Simulation Method of Wind-Induced Noise. The Fowcs Williams-Hawkings (FW-H) equation has been used to simulate the generation and propagation of sound, and the sound generated by an equivalent noise source is predicted based on the acoustic approximation model of the Lighthill equation. In this method, the near-field flow is directly obtained by the governing equation, and the acoustic pressure data are obtained by solving the integral of the other equations. When the sound pressure is calculated by integration with the FW$\mathrm{H}$ equation, the time delay between the firing and reception is taken into account by the forward projection. Thus, the sound pressure and unsteady flow field are calculated concurrently, and then the sound pressure level is obtained.

The FW-H equation is derived from the continuity equation and Navier-Stokes equation; it is as follows:

$$
\begin{aligned}
\frac{1}{a} & \frac{\partial^{2} p^{\prime}}{\partial t^{2}}-\nabla^{2} p^{\prime} \\
= & \frac{\partial^{2}}{\partial x_{i} \partial x_{j}}\left\{T_{i j} H(f)\right\} \\
& -\frac{\partial}{\partial x_{i}}\left\{\left[p_{i j} n_{j}+\rho u_{i}\left(u_{n}-v_{n}\right) \delta(f)\right]\right\} \\
& +\frac{\partial}{\partial t}\left\{\left[\rho_{0} v_{n}+\rho\left(u_{n}-v_{n}\right)\right] \delta(f)\right\}
\end{aligned}
$$

where $u_{i}$ is the velocity component of the fluid in $x_{i}$ direction, $u_{n}$ is the fluid velocity component of a vertical surface, $\delta(f)$ is the Dirac delta function, $p^{\prime}$ is the far-field sound pressure, and $H(f)$ is the Heaviside function.

\section{Simulation of the Wind Velocity Distribution around the Building}

3.1. Computational Domain, Model Geometry, and Grid Type. The factors determining the flow field and sound pressure field around the external sunshade include two main aspects: the overall flow field around the buildings and local flow around the perforation plate cavity. The building exterior flow field is determined by a wide range of building environments. To obtain detailed and accurate information of the flow, the group building model within a radius of $600 \mathrm{~m}$ around was sketched on the ICEM platform in ANSYS FLUENT 14.0, where the dimension of computational domain was $3000 \mathrm{~m} \times$ $3600 \mathrm{~m} \times 500 \mathrm{~m}(L \times W \times H$, corresponding to the $x, y$, and $z$ axes, where the $z$ axis corresponds to the height direction), respectively, providing wind with sufficient space to fully develop. The blockage ratio is $3.2 \%$, less than the threshold of $5 \%$. Group buildings model and the computational domain are shown in Figure 2.

In addition to dimension of computational domain, simulation workload is determined by grid number, which is in close relation to grid resolution. Meanwhile, grid quality is an important indicator, in relation to simulation convergence and local accuracy. The computational domain is discretized by tetrahedral unstructured grids, the minimum mesh size of the building surface is $1 \mathrm{~m}$, and the total mesh number is approximately 10 million, which is shown in Figure 3. 


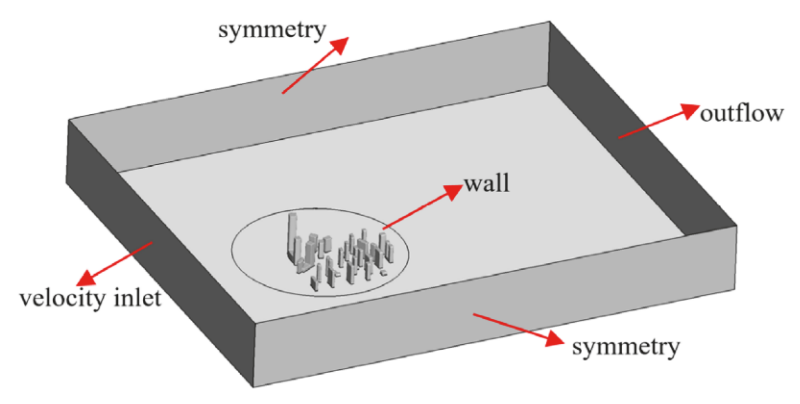

FIGURE 2: Group buildings model and the computational domain.

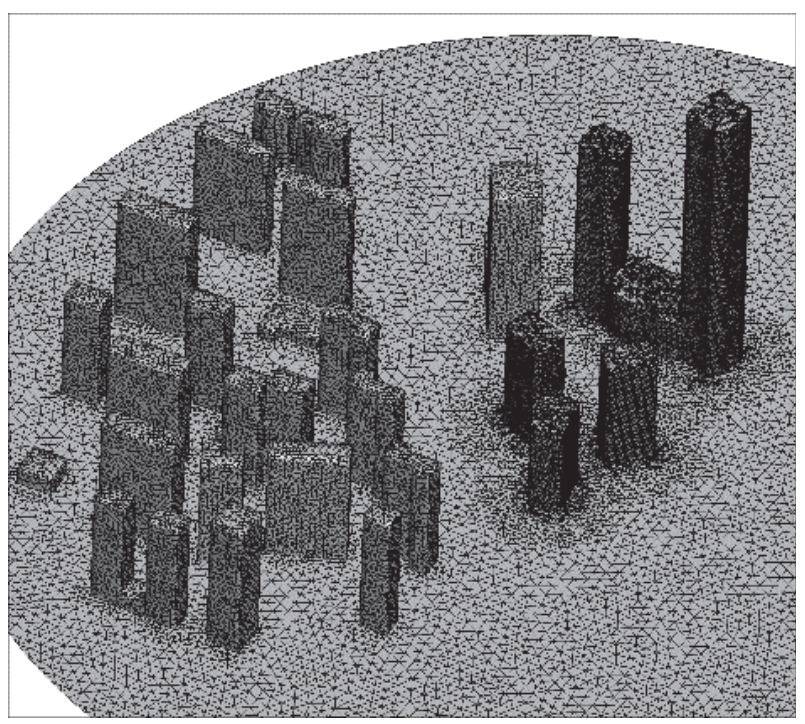

FIGURE 3: Grids on the surfaces of the buildings.

3.2. Turbulence Model and Boundary Conditions. The wind profile of large-size wind events in the atmospheric boundary layer (ABL) usually obeys logarithmic law. However, a power law formula that can estimate changes in mean wind speed with height under large-size synoptic winds is commonly used due to its simple expression [39, 40]. Therefore, the power law formula is used in 'Load Code for the Design of Building Structures of China' (GB 50009-2012) to describe mean wind speed profile and turbulence intensity profile over four different terrain categories, which are shown in [41]

$$
\begin{aligned}
& \bar{u}(z)=\bar{u}_{10} \times\left(\frac{z}{z_{10}}\right)^{\alpha} \\
& I(z)=I_{10} \times\left(\frac{z}{10}\right)^{-\alpha}
\end{aligned}
$$

where $\bar{u}(z)$ is the wind speed at the height of $z$ and $\bar{u}_{10}$ is the wind speed at the reference height of $10 \mathrm{~m}$. The power $\alpha$ is related to the terrain roughness, which is determined by terrain types. In this study, this factor is assumed to be 0.22 for all wind directions. $I(z)$ is the turbulent intensity at $z$ height, which is associated with wind flow fluctuation. $I_{10}$ is the turbulence intensity at the reference height of $10 \mathrm{~m}$ and set as 0.22 .

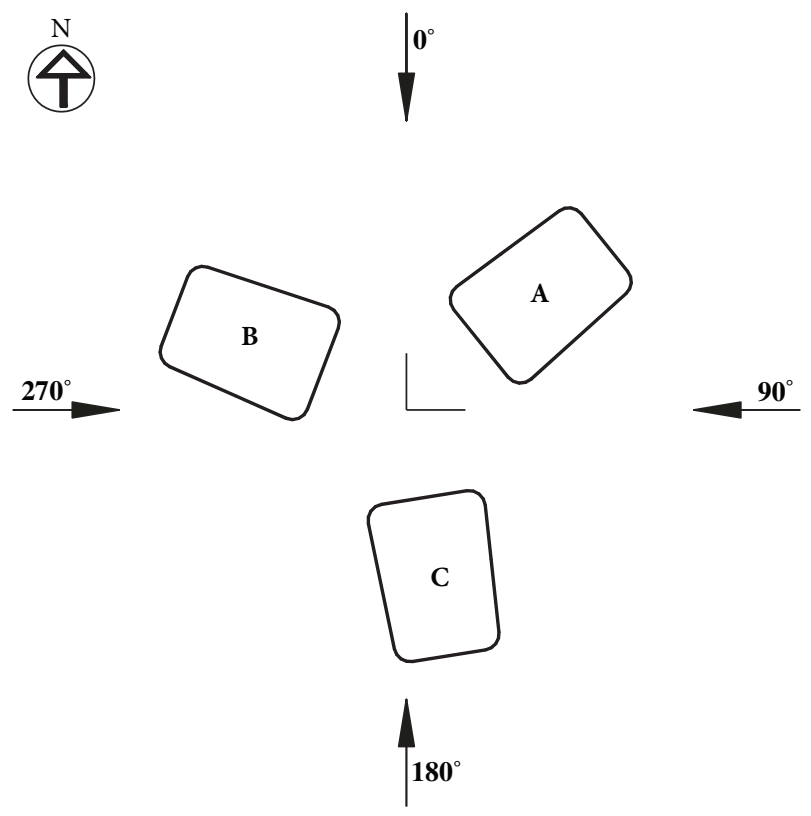

FIGURE 4: Schematic of the wind angles.

Turbulent kinetic energy $k(z)$ and turbulent dissipation rate $\varepsilon(z)$ are given in (7) and (8)[42,43]. They are used to define the inlet turbulent boundary condition.

$$
\begin{aligned}
& k(z)=1.5[I(z) \times \bar{u}(z)]^{2} \\
& \varepsilon(z)=\frac{C_{\mu}^{3 / 4} k(z)^{3 / 2}}{L_{u}}
\end{aligned}
$$

where $L_{u}$ is the characteristic length of computational domain and set as $100 \mathrm{~m} . C_{\mu}$ is an empirical constant and set as 0.09 .

Wind flow in CFD simulation has been considered as turbulent and steady but incompressible viscous fluid, which is characterized by Navier-Stokes equations. RNG $k-\varepsilon$ turbulence model was employed to perform numerical simulation. For the solver setting, SIMPLE pressure-velocity coupling algorithms were adopted, and Second-Order Upwind Scheme was adopted to discretize momentum, turbulent kinetic energy, and turbulence dissipation rate. It is assumed that simulation reaches its convergence when residuals of $\mathrm{x}, \mathrm{y}, \mathrm{z}$ momentum, $\mathrm{k}, \varepsilon$, and continuity are less than $10^{-5}$.

Figure 4 depicts the different wind angles $(\theta)$. A total of 16 wind angle simulations are conducted, with an angular interval of $22.5^{\circ}$. To not affect the result of the numerical simulation, the partial sun shading component of the building is simplified.

3.3. Wind Field Simulation Results. The wind velocity ratio (VR) is employed to assess the airflow performance of the proposed construction area and the impact between the proposed construction area and its surroundings. VR is defined by the following formula:

$$
V R=\frac{V_{p}}{V_{10}}
$$




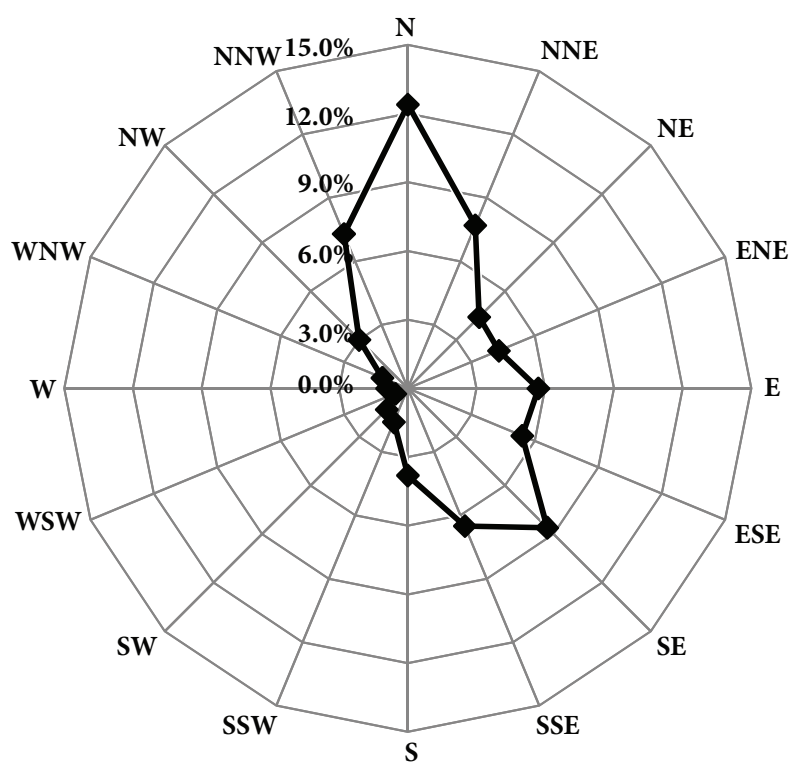

(a) Occurrence probability of wind directions

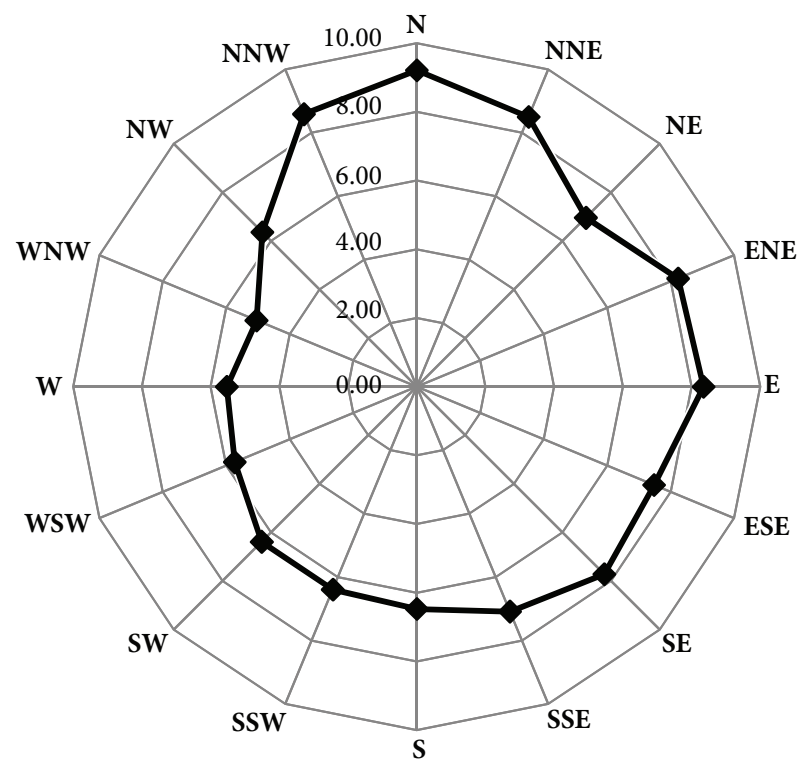

(b) Wind speeds $(\mathrm{m} / \mathrm{s})$ at the one-year return period

FIGURE 5: Occurrence probability of wind directions and speeds at a one-year return period under 16 wind directions in Guangzhou.

where $V_{10}$ represents the incident wind speed at the height of $10 \mathrm{~m}$ above the ground, which is unaffected by the downstream buildings. $V_{p}$ is the wind speed at the typical height (set as $80 \mathrm{~m}$ above the ground in this study) after taking the effects of buildings into account.

The wind speed distribution around the building can be obtained by combining the simulated wind speed ratio with the local wind climate data. Guangzhou is located in the subtropical monsoon area, and its prevailing wind direction changes significantly in the seasons. According to the statistics of the historical records of Guangzhou meteorological station (from 1962 to 2015), the prevailing wind direction in Guangzhou is north azimuth with an occurrence probability of $12.4 \%$, followed by the southeast azimuth with an occurrence probability of $8.6 \%$. Furthermore, wind speeds at a one-year return period under each wind direction can be calculated. Both the occurrence probability of wind directions and wind speeds at a one-year return period under 16 wind directions are shown in Figure 5. It can be seen that the maximum wind speed occurs in the north azimuth with a speed of $9.21 \mathrm{~m} / \mathrm{s}$. The annual wind speed can be calculated and the result shows that the average annual wind speed of Guangzhou is only $1.9 \mathrm{~m} / \mathrm{s}$. From October to March, the average wind speed is slightly larger and the speed in each month is ranging from 1.9 to $2.1 \mathrm{~m} / \mathrm{s}$. Meanwhile, the average wind speed from April to September is smaller, ranging from 1.6 to $1.9 \mathrm{~m} / \mathrm{s}$.

The wind speed distribution of a typical level under 16 wind directions is extracted. Figure 6 shows the contours of the wind speed ratio around the three towers in selected typical wind directions. It can be seen that the wind accelerated through the two tall buildings on the north side, and the wind speed is maximum at the edge area of tower $B$ at wind angle $\theta=0^{\circ}$. At wind angle $\theta=90^{\circ}$, the wind speed is higher in the passageway between tower A and the north high-rise building. There are dense residential groups on the west side of the upper reaches of the site, while the east side is relatively wide. Therefore, at wind angle $\theta=180^{\circ}$, there is no obvious interference in the upstream, and the wind speed is maximum around towers $\mathrm{A}$ and $\mathrm{B}$. At wind angle $\theta=270^{\circ}$, the shelter effect of the west residential group is obvious.

The maximum wind speed ratio $V R_{i}$ and wind speed around each tower at different wind angles are listed in Table 1 . We can see that the maximum wind speed ratio $V R_{i}$ is found around tower $\mathrm{B}$ at $\theta=0^{\circ}$ and tower $\mathrm{A}$ at $\theta=$ $22.5^{\circ}$, and the corresponding wind speed ratios are 2.80 and 2.33 , respectively. Two wind conditions are considered for the following wind-induced noise simulations of the perforation plate. The wind angle $\theta=0^{\circ}$ is the case with the maximum wind speed, and the speed of $25.8 \mathrm{~m} / \mathrm{s}$ is set as the input wind speed. On the other hand, the wind angle $\theta=0^{\circ}$ is also the case with the annual average wind speed, and the setting wind speed is $5.3 \mathrm{~m} / \mathrm{s}$.

\section{Local Wind-Induced Noise of the Perforation Plates}

Based on the results of analysis of the entire flow field around the building, the wind speed information of the typical area with maximum wind speed is extracted and the local perforation plate unit was established in detail. Then the flow field analysis and unsteady LES are performed to obtain the small-scale vortex shedding of flow around the perforation plate. Finally, the FW-H equation is solved to simulate sound generation and propagation, and the wind-induced overall sound pressure levels (OSPL) and A-weighted sound pressure levels (ASPL) are calculated to evaluate the acoustic characteristics.

The vertical sunshade component of the facade of the building curtain is a triangular hollow body surrounded by 


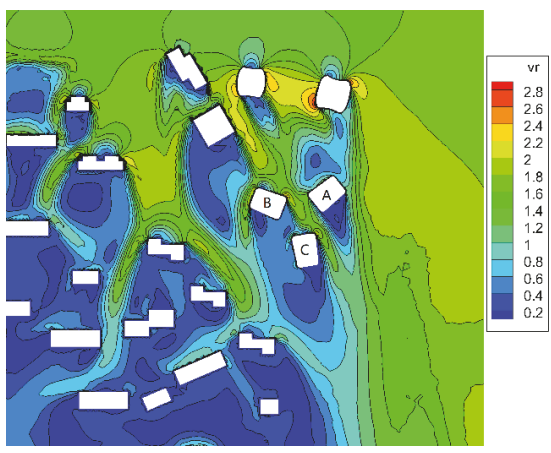

(a) $\theta=0^{\circ}$

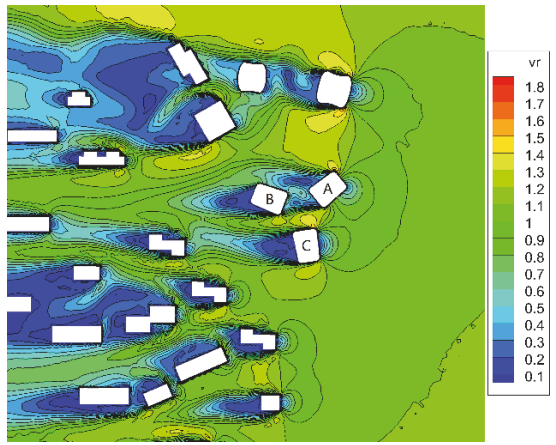

(c) $\theta=90^{\circ}$

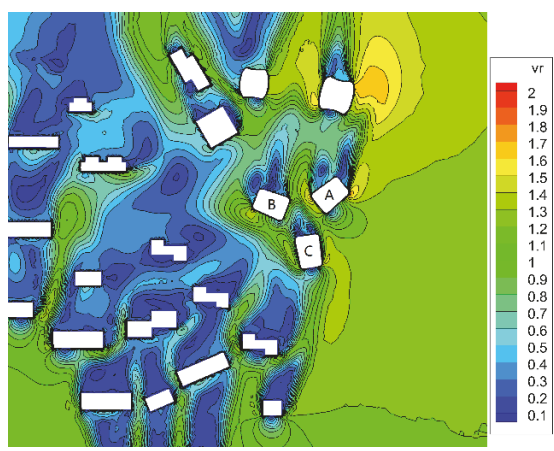

(e) $\theta=180^{\circ}$

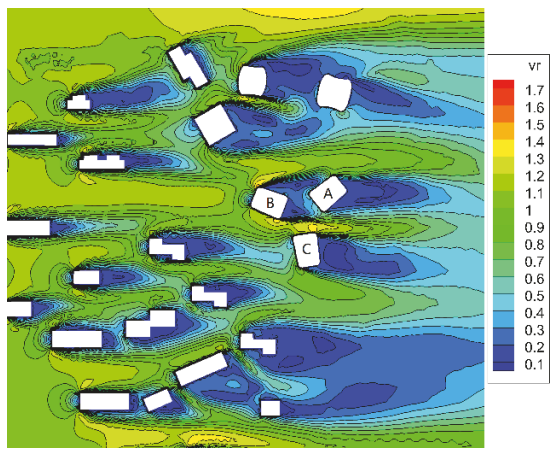

(g) $\theta=270^{\circ}$

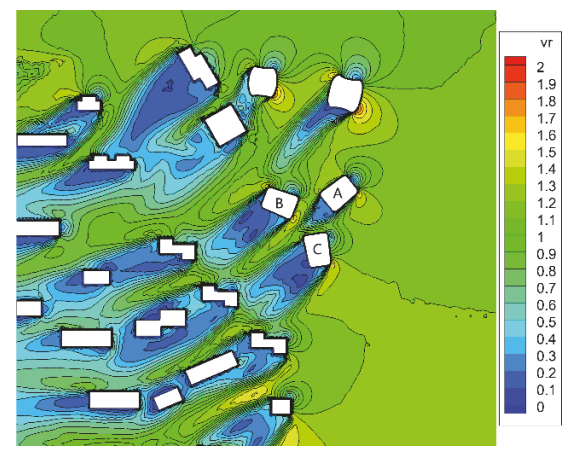

(b) $\theta=45^{\circ}$

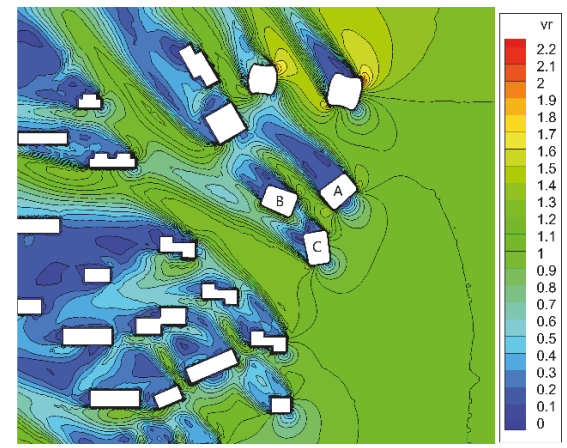

(d) $\theta=135^{\circ}$

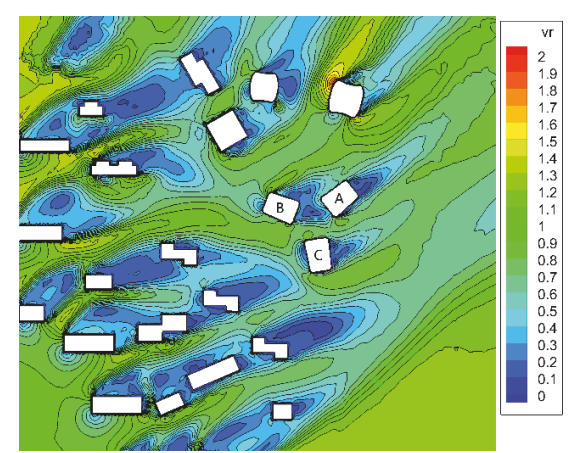

(f) $\theta=225^{\circ}$

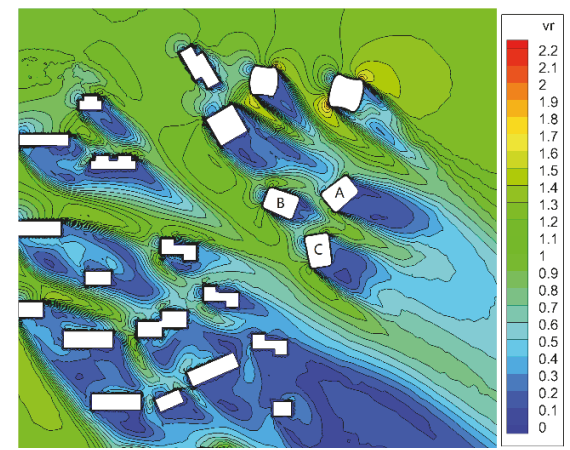

(h) $\theta=315^{\circ}$

FiguRE 6: Contours of the wind speed ratio distribution around the buildings at typical wind angles $(\theta)$. 
TABLE 1: Maximum wind speed ratio $V R_{i}$, wind speed, and its location around the building under 16 wind directions.

\begin{tabular}{|c|c|c|c|c|c|c|c|}
\hline$\theta\left(^{\circ}\right)$ & $V R_{i}$ & Speed $(\mathrm{m} / \mathrm{s})$ & Location & $\theta\left(^{\circ}\right)$ & $V R_{i}$ & Speed $(\mathrm{m} / \mathrm{s})$ & Location \\
\hline 0 & 2.80 & 25.8 & Tower B & 180 & 2.03 & 13.1 & Tower A\&B \\
\hline 22.5 & 2.33 & 19.8 & Tower A & 202.5 & 0.56 & 3.6 & Tower B \\
\hline 45 & 2.07 & 14.4 & Tower B & 225 & 1.35 & 8.6 & Tower B \\
\hline 67.5 & 2.05 & 16.9 & Tower A\&B & 247.5 & 1.46 & 8.4 & Tower B \\
\hline 90 & 1.90 & 15.9 & Tower A & 270 & 1.83 & 10.1 & Tower B \\
\hline 112.5 & 1.85 & 13.8 & Tower C & 292.5 & 1.66 & 8.4 & Tower C \\
\hline 135 & 1.83 & 14.1 & Tower C & 315.5 & 1.37 & 8.7 & Tower B\&C \\
\hline 157.5 & 2.11 & 14.9 & Tower B & 337.5 & 1.76 & 15.1 & Tower A \\
\hline
\end{tabular}

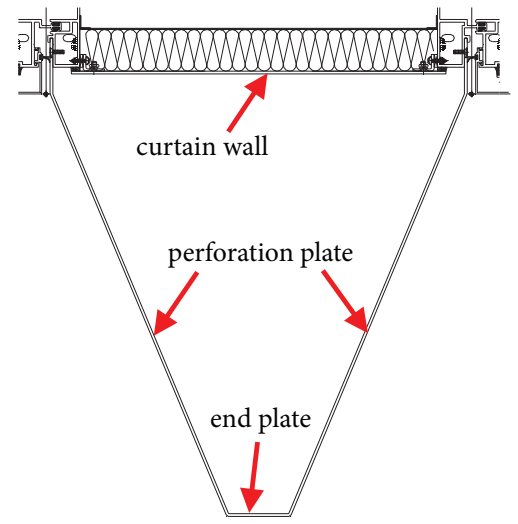

(a) Cross sectional

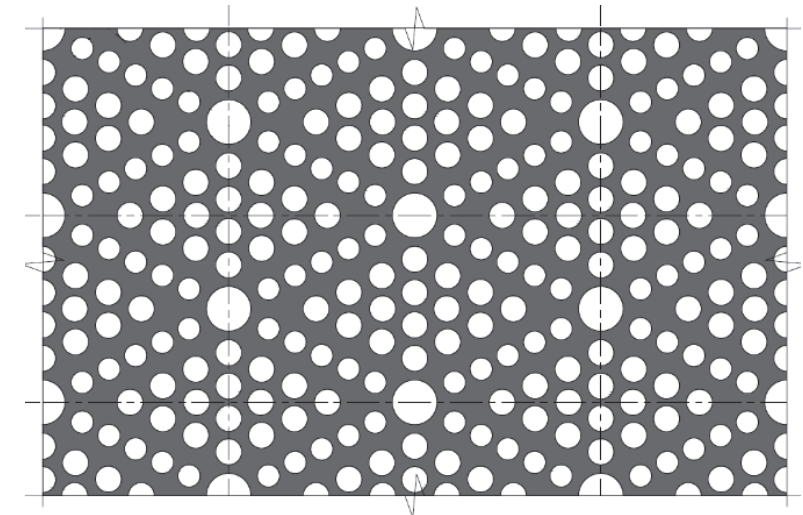

(b) Hole arrangements of the perforation plate

FIGURE 7: External sunshade perforation structure diagrammatic sketch.

perforation aluminum plates, and the cross-section of the component is shown in Figure 7(a). The two-sided plates are perforated with diamond shaped units, and the end is a long narrow solid plate. Each diamond unit is arranged regularly by three specifications of the aperture, and its plane expansion diagram is shown in Figure 7(b). To obtain a better structure of the sunshade, the wind-induced noise simulation analysis is performed for two types of perforation plate schemes. In scheme 1 , the width of the end plate is $70 \mathrm{~mm}$ and the side plate bore diameters are $6 \mathrm{~mm}, 7 \mathrm{~mm}$, and $12 \mathrm{~mm}$, whereas in scheme 2, the width of the end plate is $50 \mathrm{~mm}$, and the side plate bore diameters are $11 \mathrm{~mm}, 13 \mathrm{~mm}$, and $22 \mathrm{~mm}$.

4.1. Computational Domain and Boundary Conditions. A physical model is established according to the actual geometry and size of the sunshade, where the dimension of computational domain was $5.0 \mathrm{~m} \times 1.0 \mathrm{~m} \times 5.0 \mathrm{~m}(\mathrm{~L} \times \mathrm{W}$ $\times \mathrm{H})$. The computational domain is discretized by tetrahedral unstructured grids, the minimum mesh size of the perforation plate is $0.001 \mathrm{~m}$, and the total mesh number is approximately 4.63 million, shown in Figure 8.

The numerical calculation is performed in two stages. First, the steady-state flow field distribution and noise source location are obtained by the steady-state analysis of the flow field. In the second stage, LES is used to obtain the unsteady results. In the unsteady state simulation, the time step is set at $5.0 \times 10^{-6}$ s to capture the main sound frequency band of the human body sensitivity, and 60000 time steps are calculated.
Each wall of the perforation plate is set as a noise source when the unsteady sound pressure field is simulated, and the sound pressure signal files are stored after every 500 time steps. After the calculation, a series of sound pressure time history data can be obtained. To analyze the noise generated by the flow field around the sunshade, a series of acoustic pressure receiving points (receiver) are defined on the windward side of the perforation plate, inside of the cavity, leeward side, and position of the attachment. The maximum distance between the holes and receivers is $1.25 \mathrm{~m}$. The exact location of the receiving points is shown in Figure 8(c).

4.2. Sound Pressure Level of the Receiving Points. OSPL can be obtained by accumulating the sound pressure level produced by all sources at the receiving point. Nevertheless, because the response of the human ear to the sound at different frequencies is different, the OSPL which is obtained by accumulating all the sound pressure at all frequencies cannot fully reflect the nonlinear response of the human ear to the sound frequency. Compared with the overall sound pressure level, A-weighted sound level reflects the human ear frequency response more accurately. When calculating the A-weighted sound level, the sound pressure level is reduced according to the formula before the low-frequency and highfrequency sound pressure levels are added together.

For the maximum wind speed condition at 1-year return period, the OSPL and ASPL at the receiving points near the 


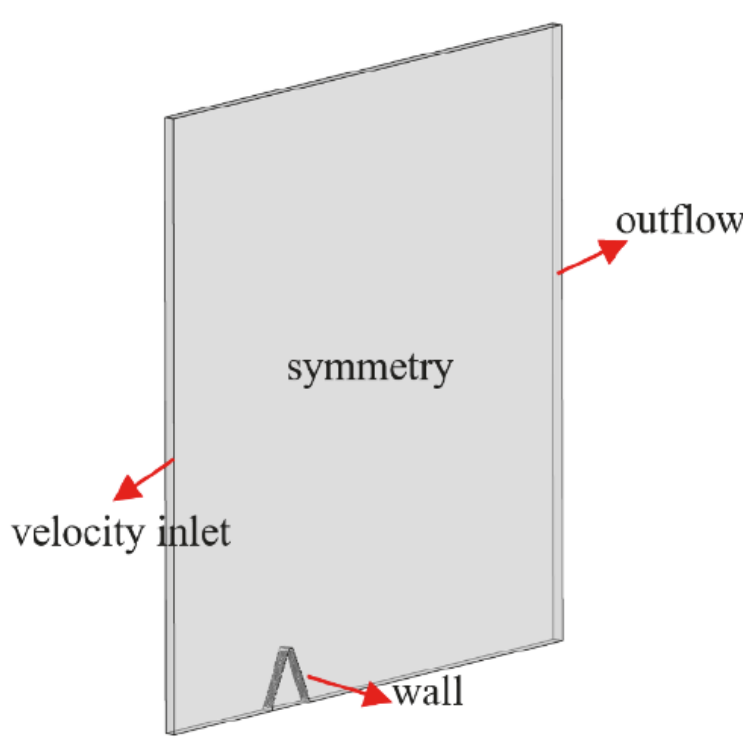

(a) Computational domain

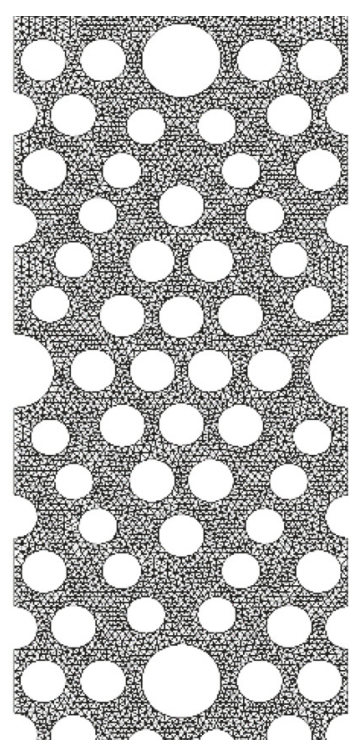

(b) Grid distribution

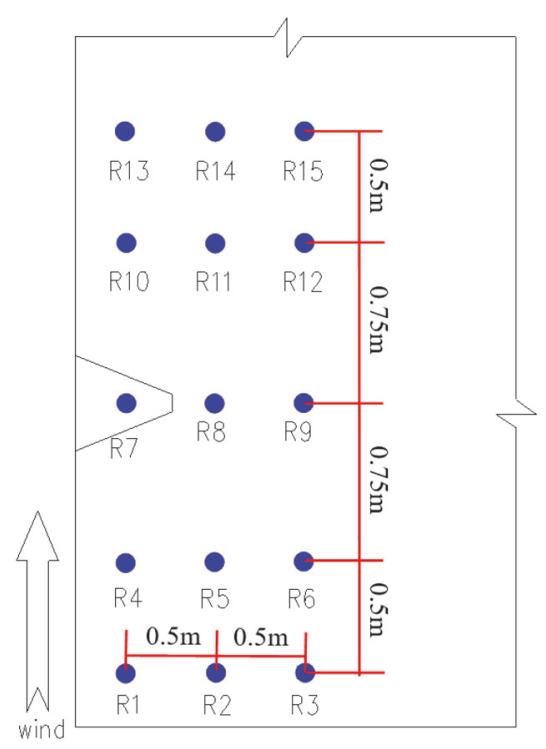

(c) Receiving points

FIGURE 8: Computational domain, grid distribution, and sound pressure receiving points' diagrammatic sketch.

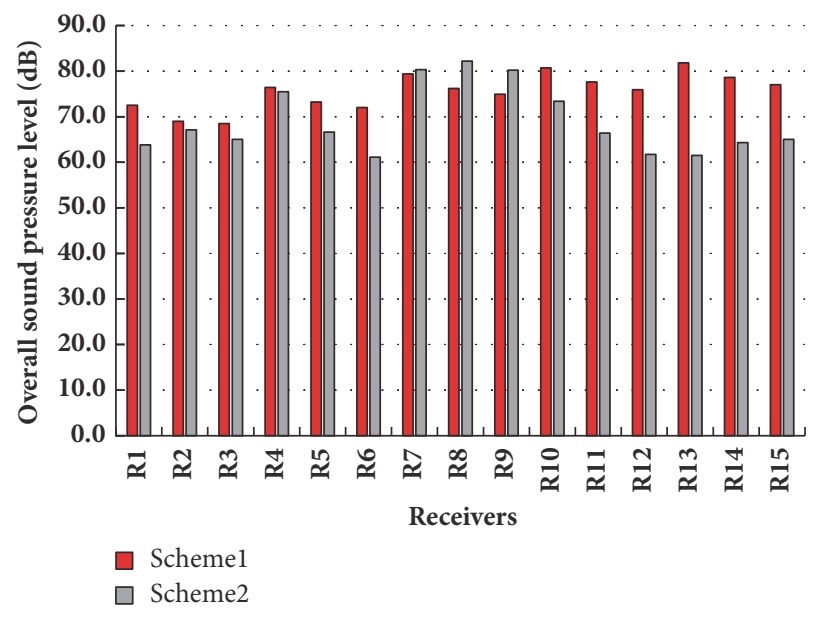

(a) OSPL

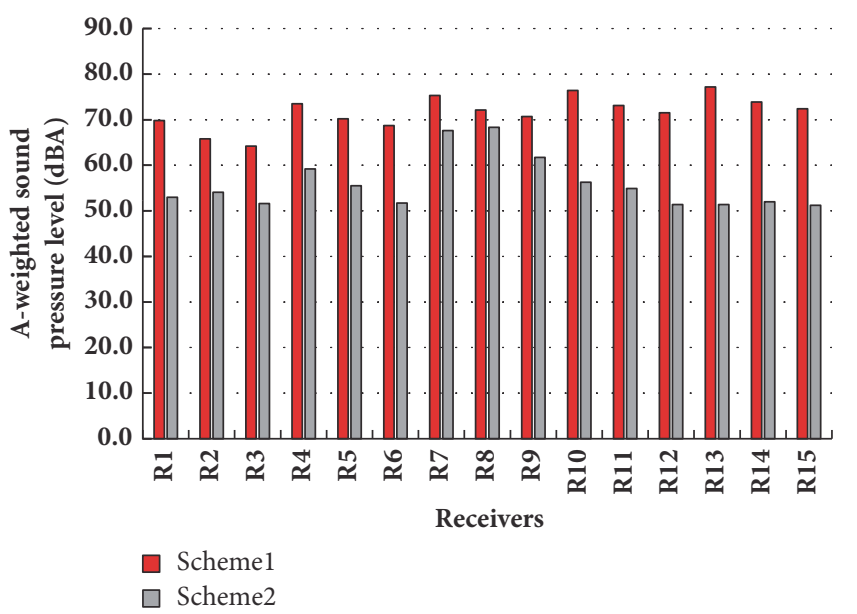

(b) ASPL

FIGURE 9: Comparison with sound pressure level of each receiver for the maximum wind speed condition at 1-year return period.

shading devices under the two schemes are shown in Figures 9(a) and 9(b). For scheme 1, the OSPL in a perforation plate receiving point $\mathrm{R} 1$, cavity internal receiving point $\mathrm{R} 7$, and perforation plate leeward downstream receiving point $\mathrm{R} 10$ are $73 \mathrm{~dB}, 79 \mathrm{~dB}$, and $81 \mathrm{~dB}$, respectively, and the corresponding ASPL are $70 \mathrm{~dB}(\mathrm{~A}), 75 \mathrm{~dB}(\mathrm{~A})$, and $76 \mathrm{~dB}(\mathrm{~A})$. For scheme 2 , the OSPL in R1, R7, and R10 are $64 \mathrm{~dB}, 80 \mathrm{~dB}$, and 73 $\mathrm{dB}$, respectively, and the corresponding ASPL are $53 \mathrm{~dB}(\mathrm{~A})$, $68 \mathrm{~dB}(\mathrm{~A})$, and $56 \mathrm{~dB}(\mathrm{~A})$, respectively. Scheme 2 effectively reduces the level of wind-induced noise by reducing the width of the end plate and increasing the size of the perforation.

For the annual average wind speed condition, the OSPL and ASPL at the receiving points near the shading devices under the two schemes are shown in Figures 10(a) and 10(b). For scheme 1, the OSPL in R1, R7, and R10 are $58 \mathrm{~dB}, 72 \mathrm{~dB}$, and $72 \mathrm{~dB}$, respectively, and the corresponding ASPL are 45 $\mathrm{dB}(\mathrm{A}), 54 \mathrm{~dB}(\mathrm{~A})$, and $53 \mathrm{~dB}(\mathrm{~A})$, respectively. The OSPL in $\mathrm{R} 1, \mathrm{R} 7$, and $\mathrm{R} 10$ are changed to $36 \mathrm{~dB}, 58 \mathrm{~dB}$, and $50 \mathrm{~dB}$; the corresponding ASPL are changed to $24 \mathrm{~dB}(\mathrm{~A}), 45 \mathrm{~dB}(\mathrm{~A})$, and $33 \mathrm{~dB}(\mathrm{~A})$ for scheme 2 .

4.3. Sound Pressure Level of Receivers in Frequency Domain. To analyze the mechanism of wind-induced noise in the two schemes, the distribution curve of sound pressure intensity in each frequency range could be obtained by fast Fourier transform of the sound pressure time history obtained at each monitoring point. The $1 / 3$ octave sound pressure distributions of the key points R1, R7, and R10 under two schemes are given in Figures 11 and 12, respectively, for the maximum wind speed condition at 1 -year return period. As shown in 


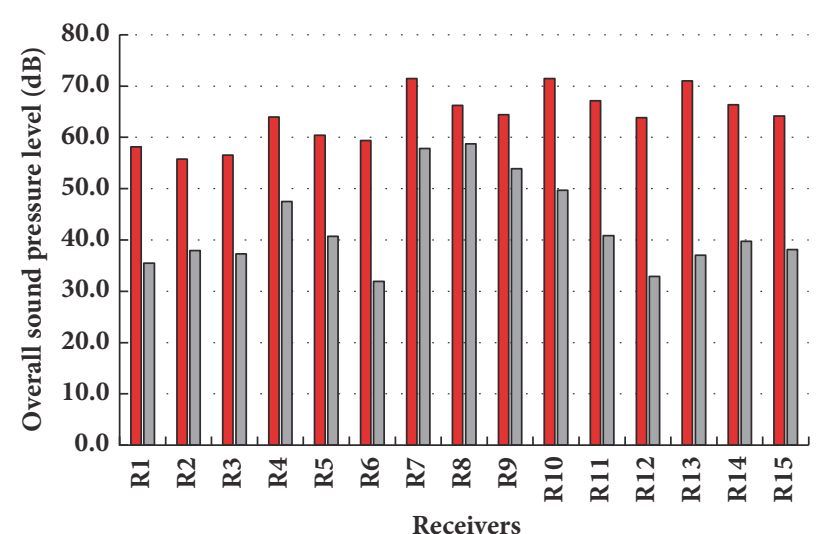

Scheme1

$\square$ Scheme2

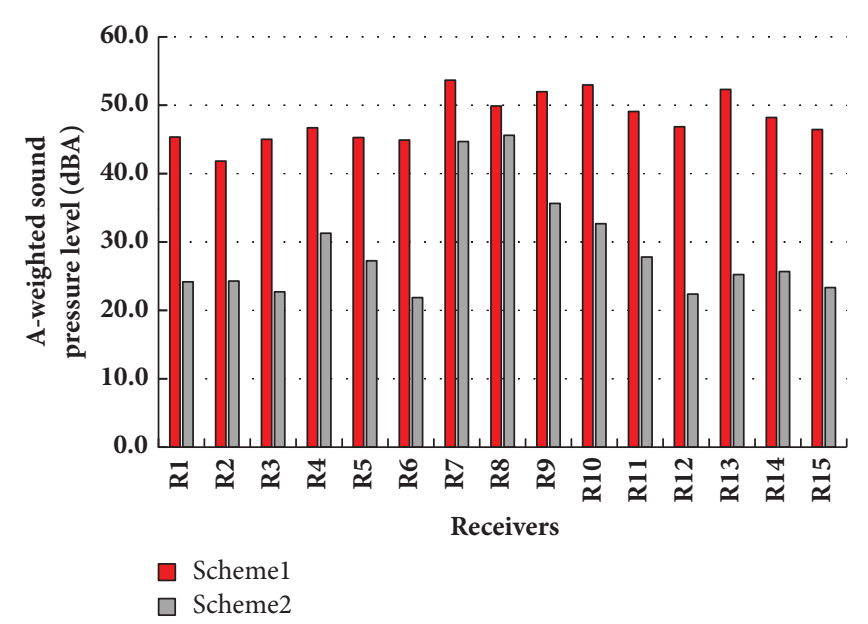

(b) ASPL

FIGURE 10: Comparison with sound pressure level of each receiver for the annual average wind speed condition.

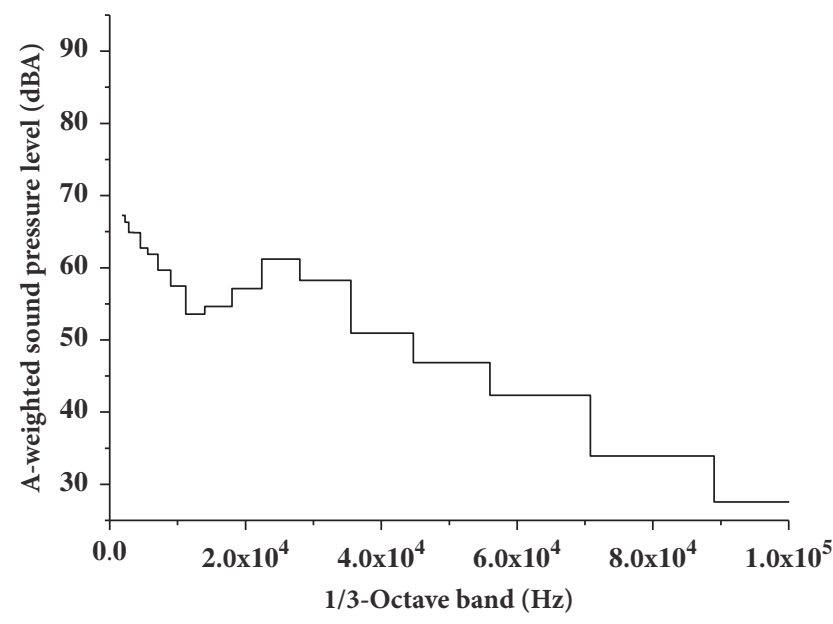

(a) Receiver 1

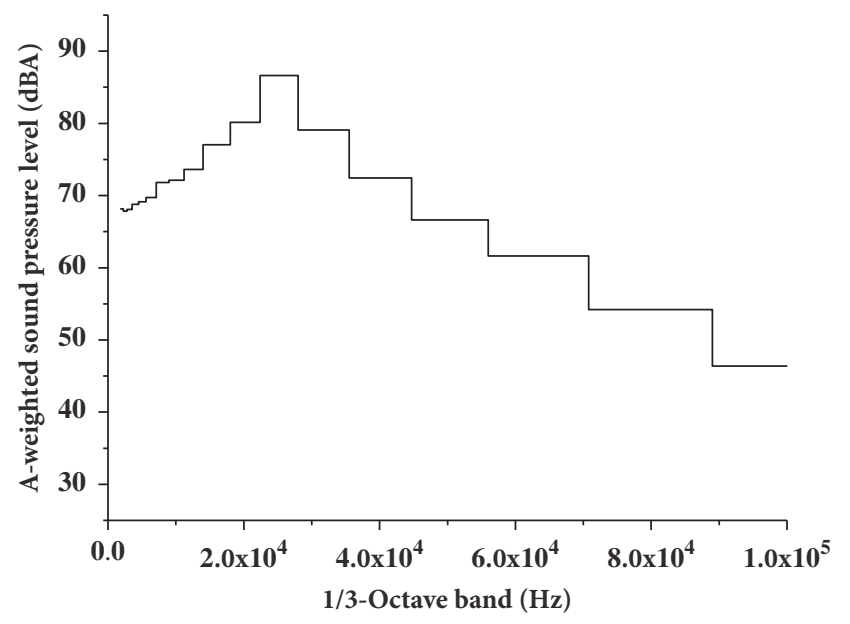

(b) Receiver 7

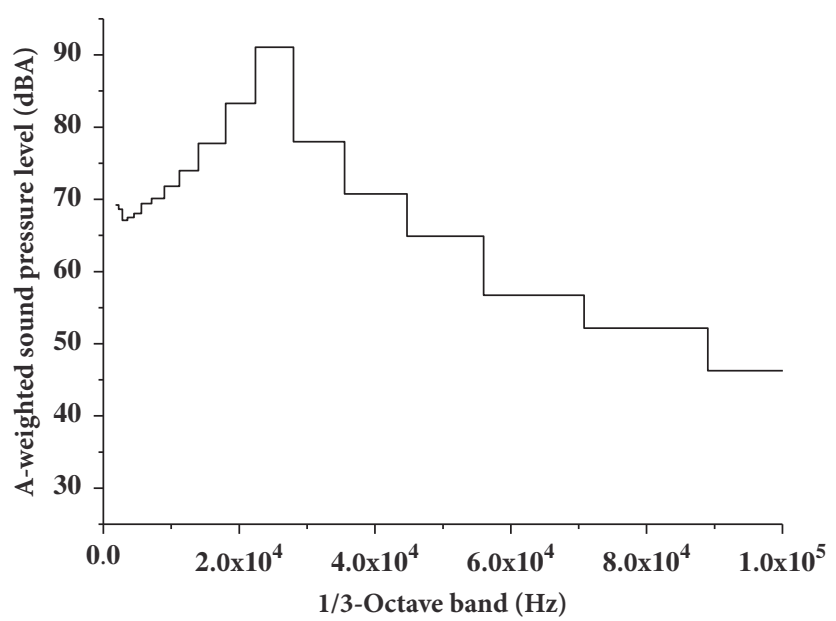

(c) Receiver 10

FIGURE 11: Sound pressure level distribution of typical receivers under scheme 1. 


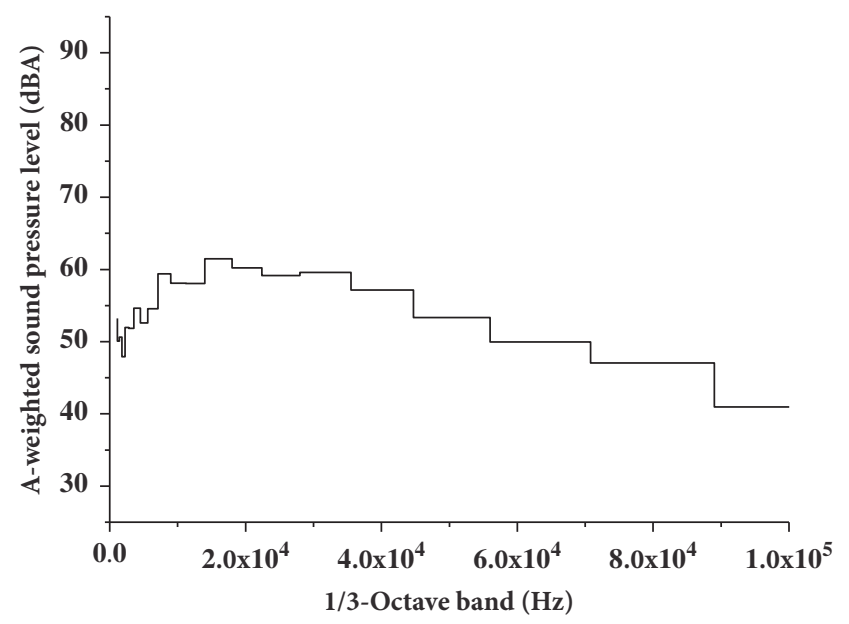

(a) Receiver 1

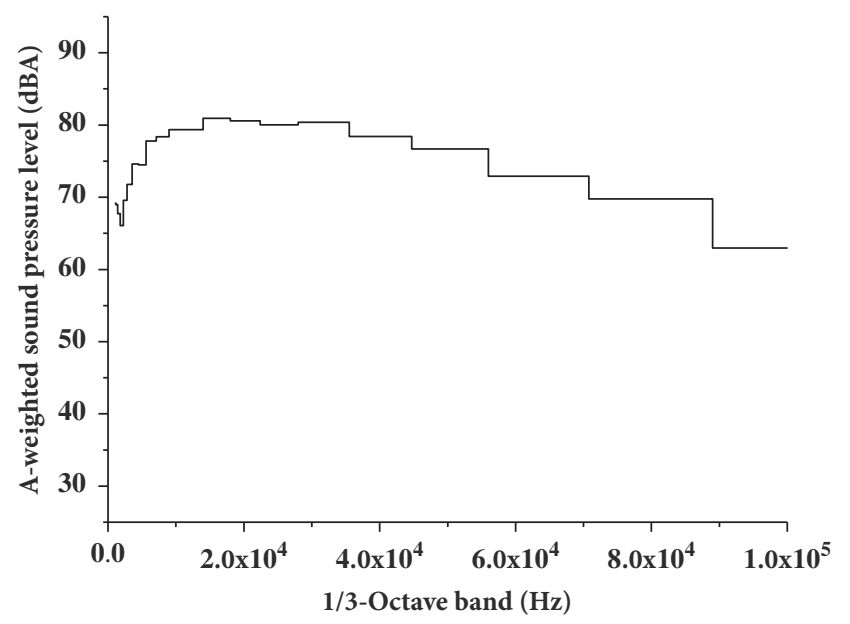

(b) Receiver 7

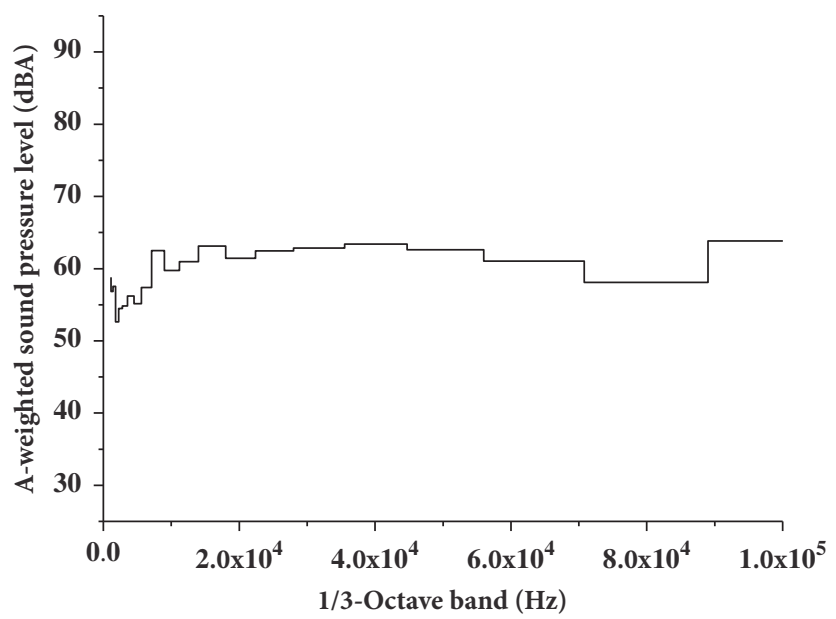

(c) Receiver 10

FIGURE 12: Sound pressure level distribution of typical receivers under scheme 2.

the diagrams, in scheme 1 , the sound pressure distribution at each monitoring point has obvious peaks at $2000 \sim 4000 \mathrm{~Hz}$ frequency section, whereas in scheme 2 , the sound pressure frequency distribution tends to be flat. Thus, the aerodynamic characteristics of the perforation plate can be enhanced by varying the width of the end plate and increasing the size of the perforation.

\section{Conclusion}

In this study, Reynolds-averaged Navier-Stokes (RANS) simulations, large-eddy simulations (LES), and Lighthill's acoustic method have been conducted to study flow around high-rise buildings with external sunshade curtain wall. Both the wind speed distributions around the buildings and the sound pressure levels in the vicinity of the shading devices have been analyzed. The main findings are summarized as follows.

(1) According to the statistics of the historical records of Guangzhou meteorological station, the maximum wind occurs in the north azimuth with a speed of $9.21 \mathrm{~m} / \mathrm{s}$ at 1-year return period. The average annual wind speed of Guangzhou is only $1.9 \mathrm{~m} / \mathrm{s}$.

(2) The maximum wind speed around the buildings exists at the building corners under all simulated 16 wind directions. The maximum wind speed ratio is 2.8 , which occurs at 0 degree wind direction.

(3) The overall sound pressure level (OSPL) and Aweighted sound pressure level (ASPL) around the shading devices are $80 \mathrm{~dB}$ and $68 \mathrm{~dB}(\mathrm{~A})$ for perforation plate scheme 2 under the 1-year return period maximum speed, which are reduced to $58 \mathrm{~dB}$ and $45 \mathrm{~dB}(\mathrm{~A})$ under the annual average speed.

(4) The aeroacoustic performance of perforation plate scheme 2 is better than that of perforation plate scheme 1 , because wind-induced noise caused by the shading devices has been reduced effectively. Therefore, it is believed that perforation plates with small end plate size and large aperture size are desirable for the noise prevention design of shading devices. 


\section{Data Availability}

The data used to support the findings of this study are available from the corresponding author upon request.

\section{Conflicts of Interest}

The authors declare that there are no conflicts of interest regarding the publication of this article.

\section{Acknowledgments}

This research was funded by the National Natural Sciences Foundation of China (NSFC) (51778199), the Natural Science Foundation of Guangdong Province (2017A030313324), and the National Key Research and Development Program of China (2016YFC0701107).

\section{References}

[1] J. Ball, "Can ISO 14000 and eco-labelling turn the construction industry green?” Building and Environment, vol. 37, no. 4, pp. 421-428, 2002.

[2] Y.-H. Lin, K.-T. Tsai, M.-D. Lin, and M.-D. Yang, "Design optimization of office building envelope configurations for energy conservation," Applied Energy, vol. 171, pp. 336-346, 2016.

[3] M. Charde and R. Gupta, "Design development and thermal performance evaluation of static sunshade and brick cavity wall: An experimental study," Energy and Buildings, vol. 60, pp. 210216, 2013.

[4] N. K. Kapur, "A comparative analysis of the radiant effect of external sunshades on glass surface temperatures," Solar Energy, vol. 77, no. 4, pp. 407-419, 2004.

[5] A. M. Aly and S. Abburu, "On the design of high-rise buildings for multihazard: fundamental differences between wind and earthquake demand," Shock and Vibration, vol. 2015, 22 pages, 2015.

[6] X. P. Liu, J. L. Niu, and K. C. S. Kwok, "Analysis of concentration fluctuations in gas dispersion around high-rise building for different incident wind directions," Journal of Hazardous Materials, vol. 192, no. 3, pp. 1623-1632, 2011.

[7] Q. X. Li, "Analysis of the wind-induced noise of a porous ventilator used in indoor natural ventilation based on CFD simulation," Guangdong Architecture and Civil Engineering, no. 2, pp. 37-40, 2011.

[8] A. Ruiz-Padillo, D. P. Ruiz, A. J. Torija, and Á. Ramos-Ridao, "Selection of suitable alternatives to reduce the environmental impact of road traffic noise using a fuzzy multi-criteria decision model," Environmental Impact Assessment Review, vol. 61, pp. 8-18, 2016.

[9] J. Morel, C. M. Favre, and L.-A. Gille, "Noise annoyance assessment of various urban road vehicle pass-by noises in isolation and combined with industrial noise: a laboratory study," Applied Acoustics, vol. 101, pp. 47-57, 2016.

[10] G. Licitra, L. Fredianelli, D. Petri, and M. A. Vigotti, "Annoyance evaluation due to overall railway noise and vibration in Pisa urban areas," Science of the Total Environment, vol. 568, pp. 13151325, 2016.

[11] F. Bunn and P. H. T. Zannin, "Assessment of railway noise in an urban setting," Applied Acoustics, vol. 104, pp. 16-23, 2016.
[12] P. Gagliardi, L. Fredianelli, D. Simonetti, and G. Licitra, "ADS$\mathrm{B}$ system as a useful tool for testing and redrawing noise management strategies at Pisa Airport," Acta Acustica united with Acustica, vol. 103, no. 4, pp. 543-551, 2017.

[13] C. Iglesias-Merchan, L. Diaz-Balteiro, and M. Soliño, “Transportation planning and quiet natural areas preservation: Aircraft overflights noise assessment in a National Park," Transportation Research Part D: Transport and Environment, vol. 41, pp. 1-12, 2015.

[14] H. M. E. Miedema and C. G. M. Oudshoorn, "Annoyance from transportation noise: relationships with exposure metrics DNL and DENL and their confidence intervals," Environmental Health Perspectives, vol. 109, no. 4, pp. 409-416, 2001.

[15] F. Minichilli, F. Gorini, E. Ascari et al., "Annoyance judgment and measurements of environmental noise: a focus on Italian secondary schools," International Journal of Environmental Research and Public Health, vol. 15, no. 2, pp. 208-218, 2018.

[16] J. Dratva, H. C. Phuleria, M. Foraster et al., “Transportation noise and blood pressure in a population-based sample of adults," Environmental Health Perspectives, vol. 120, no. 1, pp. 50-55, 2012.

[17] S. A. Janssen, H. Vos, A. R. Eisses, and E. Pedersen, "A comparison between exposure-response relationships for wind turbine annoyance and annoyance due to other noise sources," The Journal of the Acoustical Society of America, vol. 130, no. 6, pp. 3746-3753, 2011.

[18] D. P. Knobles, S. M. Joshi, R. D. Gaul, H. C. Graber, and N. J. Williams, "Analysis of wind-driven ambient noise in a shallow water environment with a sandy seabed," The Journal of the Acoustical Society of America, vol. 124, no. 3, pp. EL157-EL162, 2008.

[19] S. Najeem, M. C. Sanjana, G. Latha, and P. Edwards Durai, "Wind induced ambient noise modelling and comparison with field measurements in Arabian Sea," Applied Acoustics, vol. 89, pp. 101-106, 2015.

[20] N. Sedaghatizadeh, M. Arjomandi, B. Cazzolato, and R. Kelso, "Wind farm noises: mechanisms and evidence for their dependency on wind direction," Journal of Renewable Energy, vol. 109, pp. 311-322, 2017.

[21] P. Ma, F. S. Lien, and E. Yee, "Coarse-resolution numerical prediction of small wind turbine noise with validation against field measurements," Journal of Renewable Energy, Part B, vol. 102, pp. 502-515, 2017.

[22] R. G. Zhang and S. Kanapathipillai, "A study of wind induced noise in microphones," in Proceedings of the Acoustics, pp. 1-4, Geelong, Australia, 2008.

[23] S. V. Alamshah and A. C. Zander, "Development of a technique to minimise the windinduced noise in shielded microphones," in Proceedings of the Acoustics, pp. 1-8, Victor Harbor, Australia, 2013.

[24] S. V. Alamshah, A. C. Zander, and V. Lenchine, "Effects of turbulent flow characteristics on wind induced noise generation in shielded microphones," in Proceedings of the Acoustics, pp. 111, Sydney, Australia, 2015.

[25] B. Chen, Q. Wei, T. Shao, Y. Li, and X. Huang, "Aeroacoustic imaging experiments of airframe noise in lined wall closedsection wind tunnel," Journal of Aerospace Engineering, vol. 28, no. 4, Article ID 04014090, 2015.

[26] P. Liu, Y. Xing, H. Guo, and L. Li, "Design and performance of a small-scale aeroacoustic wind tunnel," Applied Acoustics, vol. 116, pp. 65-69, 2017. 
[27] Y. C. CansevKüçükosman, C. Schram, and J. van Beeck, "A remote microphone technique for aeroacoustic measurements in large wind tunnels," Applied Acoustics, vol. 129, pp. 346-353, 2018.

[28] V. Clair, C. Polacsek, T. Le Garrec, G. Reboul, M. Gruber, and P. Joseph, "Experimental and numerical investigation of turbulence-airfoil noise reduction using wavy edges," AIAA Journal, vol. 51, no. 11, pp. 2695-2713, 2013.

[29] Y. S. Wang, L. N. Sui, Z. Y. Yin, X. L. Wang, N. N. Liu, and $\mathrm{H}$. Guo, "A hybrid prediction for wind buffeting noises of vehicle rear window based on LES-LAA method," Applied Mathematical Modelling, vol. 47, pp. 160-173, 2017.

[30] P. Gallo, L. Fredianelli, D. Palazzuoli, G. Licitra, and F. Fidecaro, "A procedure for the assessment of wind turbine noise," Applied Acoustics, vol. 114, pp. 213-217, 2016.

[31] Y. D. Zhang, J. Y. Zhang, T. Li, L. Zhang, and W. Zhang, "Research on aerodynamic noise reduction for high-speed trains," Shock and Vibration, vol. 2016, Article ID 6031893, 21 pages, 2016.

[32] M. H. Mohamed, "Reduction of the generated aero-acoustics noise of a vertical axis wind turbine using CFD (Computational Fluid Dynamics) techniques," Energy, vol. 96, pp. 531-544, 2016.

[33] I. Hashem, M. H. Mohamed, and A. A. Hafiz, "Aero-acoustics noise assessment for Wind-Lens turbine," Energy, vol. 118, pp. 345-368, 2017.

[34] D. Li, F. Zhang, J. Long, and D. Luo, “The numerical simulation of a rectifying device with a perforated plate," Flow Measurement \& Instrumentation, vol. 38, no. 8, pp. 27-35, 2014.

[35] F. Qu and J. Kang, "Effects of built environment morphology on wind turbine noise exposure at building façades," Journal of Renewable Energy, vol. 107, pp. 629-638, 2017.

[36] Y. Wang, Y. Deng, Z. Yang, T. Jiang, C. Su, and X. Yang, "Numerical study of the flow-induced sunroof buffeting noise of a simplified cavity model based on the slightly compressible model," Proceedings of the Institution of Mechanical Engineers, Part D: Journal of Automobile Engineering, vol. 227, no. 8, pp. 1187-1199, 2013.

[37] Y. Kim, Y. Joni Tri, and S. Baek, "A study on numerical simulation on flow-fields and wind-induced noise around buildings," in Proceedings of the 7th Asia-Pacific Conference on Wind Engineering, pp. 1-8, Taipei, Taiwan, November 2009.

[38] N. Z. Martello, S. Secchi, P. Fausti, G. Cellai, and A. Santoni, "Analysis of direct and flanking sound transmission between rooms with curtain wall facades," International Building Physics Conference, vol. 10, no. 3, pp. 485-487, 2015.

[39] A. M. Aly, "Atmospheric boundary-layer simulation for the built environment: Past, present and future," Building and Environment, vol. 75, pp. 206-221, 2014.

[40] C. W. Kent, S. Grimmond, D. Gatey, and J. F. Barlow, "Assessing methods to extrapolate the vertical wind-speed profile from surface observations in a city centre during strong winds," Journal of Wind Engineering \& Industrial Aerodynamics, vol. 75, pp. 206-221, 2017.

[41] GB 50009-2010, Load Code for the Design of Building Structures of China, The Ministry of Construction of China, Beijing, China, 2012.

[42] B. Mou, B.-J. He, D.-X. Zhao, and K.-W. Chau, "Numerical simulation of the effects of building dimensional variation on wind pressure distribution," Engineering Applications of Computational Fluid Mechanics, vol. 11, no. 1, pp. 293-309, 2017.
[43] D.-X. Zhao and B.-J. He, "Effects of architectural shapes on surface wind pressure distribution: case studies of oval-shaped tall buildings," Journal of Building Engineering, vol. 12, pp. 219228,2017 


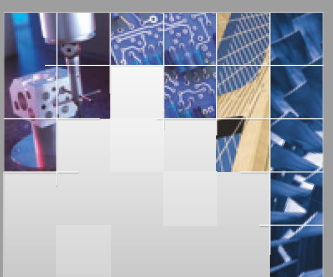

\section{Enfincering}
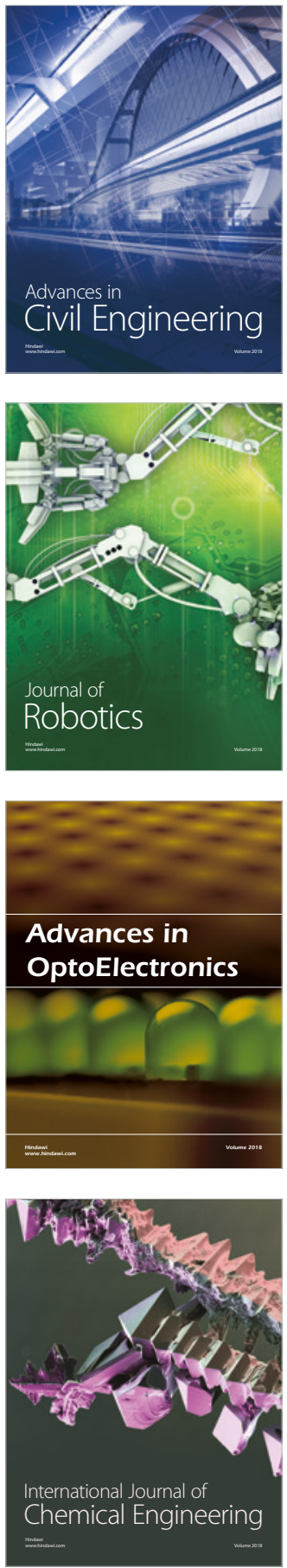

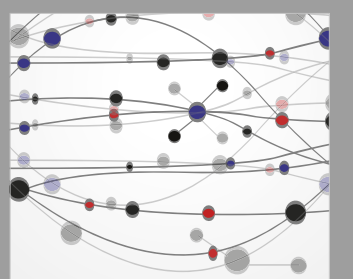

\section{Rotating \\ Machinery}

The Scientific World Journal

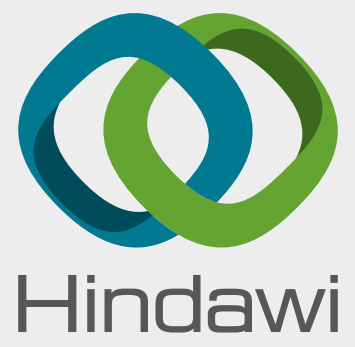

Submit your manuscripts at

www.hindawi.com
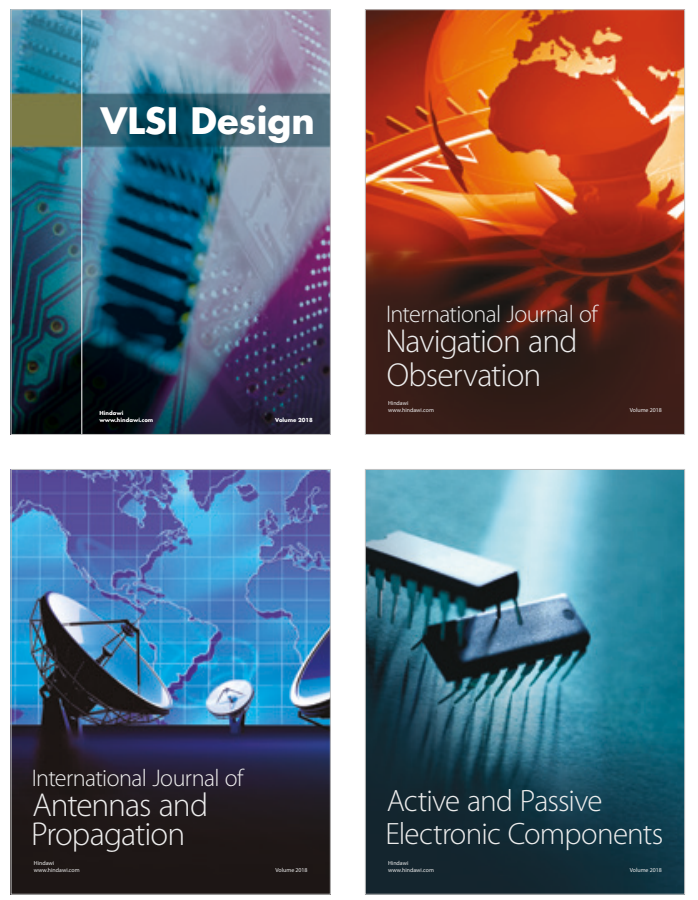
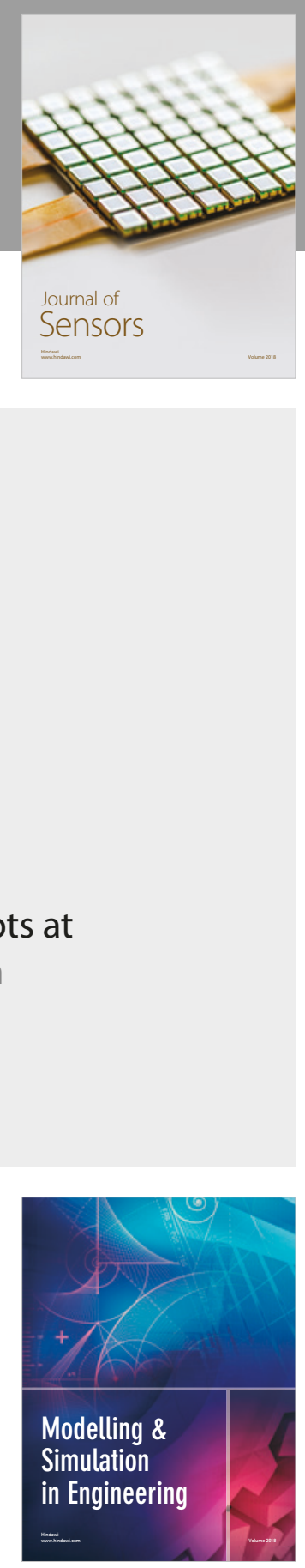

\section{Advances \\ Multimedia}
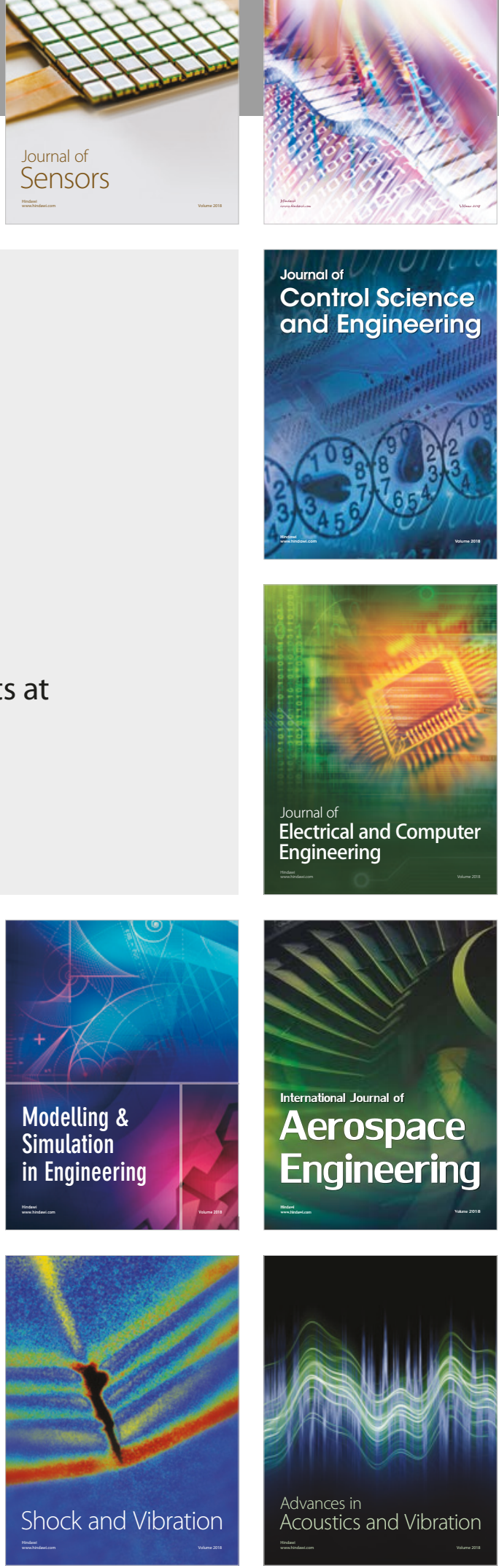